\title{
DDT contamination from indoor residual spraying for malaria control
}

\author{
J.C. Van Dyk ${ }^{\text {a,* }}$, H. Bouwman ${ }^{\text {b }}$, I.E.J. Barnhoorn ${ }^{\text {a }}$, M.S. Bornman ${ }^{\text {a }}$ \\ a Department of Urology, University of Pretoria, PO Box 667, Pretoria 0001, South Africa \\ b School of Environmental Sciences and Development, North-West University, Private Bag X6001 Potchefstroom 2520, South Africa
}

\section{A R T I C L E I N F O}

\section{Article history:}

Received 4 September 2009

Received in revised form 7 February 2010

Accepted 2 March 2010

Available online $\mathrm{xxxx}$

\section{Keywords:}

DDT

Insecticide

Domestic environment

Limpopo Province

South Africa

\begin{abstract}
A B S T R A C T
The insecticide DDT is still used in specific areas of South Africa for indoor residual spray (IRS) to control malaria vectors. Local residents could be exposed to residues of DDT through various pathways including indoor air, dust, soil, food and water. The aims of this study were to determine the levels of DDT contamination, as a result of IRS, in representative homesteads, and to evaluate the possible routes of human exposure. Two villages, exposed (DV) and reference (TV) were selected. Sampling was done two months after the IRS process was completed. Twelve homesteads were selected in DV and nine in TV. Human serum, indoor air, floor dust, outside soil, potable water, leafy vegetables, and chicken samples (muscle, fat and liver) were collected and analyzed for both the $o, p^{\prime}$ - and $p, p^{\prime}$-isomers of DDT, DDD and DDE. DDT was detected in all the media analyzed indicating a combination of potential dietary and non-dietary pathways of uptake. DV had the most samples with detectable levels of DDT and its metabolites, and with the exception of chicken muscle samples, DV also had higher mean levels for all the components analyzed compared to TV. Seventy-nine percent of participants from DV had serum levels of DDT (mean $\sum$ DDT $7.3 \mu \mathrm{g} \mathrm{g}^{-1}$ lipid). These residues constituted mainly of $p, p^{\prime}$-DDD and $p, p^{\prime}$-DDE. $\sum$ DDT levels were detected in all indoor air (mean $\sum$ DDT $3900.0 \mathrm{ng} \mathrm{m}^{-3}$ ) and floor dust (mean $\sum$ DDT $1200.0 \mu \mathrm{g} \mathrm{m}^{-2}$ ) samples. Levels were also detected in outside soil (mean $\sum$ DDT $25.0 \mu \mathrm{g} \mathrm{kg}^{-1}$ ) and potable water (mean $\sum$ DDT $2.0 \mu \mathrm{g} \mathrm{L}^{-1}$ ). Vegetable sample composition (mean $\sum$ DDT $43.0 \mu \mathrm{g} \mathrm{kg}^{-1}$ ) constituted mainly $p, p^{\prime}$-DDT and $p, p^{\prime}$-DDD. Chicken samples were highly contaminated with DDT (muscle mean $\sum$ DDT $700.0 \mu \mathrm{g} \mathrm{kg}^{-1}$, fat mean $\sum$ DDT $240,000.0 \mu \mathrm{kg}^{-1}$, liver mean $\sum$ DDT $1600.0 \mu \mathrm{g} \mathrm{kg}^{-1}$ ). The results of the current study raise concerns regarding the potential health effects in residents living in the immediate environment following DDT IRS.
\end{abstract}

(C) 2010 Elsevier B.V. All rights reserved.

\section{Introduction}

Rural villages in the northern and eastern parts of the Vhembe District of the Limpopo Province in South Africa are located in an intermediate- to high-risk malaria area (DoH, 2005). The insecticide dichloro-diphenyl-trichloroethane (DDT) is still used for the purpose of malaria vector control (LSDI, 2003). The Stockholm Convention on Persistent Organic Pollutants (POPs) of 2001, a treaty to reduce and/or eliminate the release of POPs into the environment, allows for countries like South Africa, to manage malaria transmission by using DDT specifically for Indoor Residual Spray (IRS) purposes. DDT has been used in South Africa for IRS malaria control since the 1940s. In 1996, DDT was replaced with pyrethroids. However, after the emergence of the pyrethroid-resistant strain of Anopheles funestus, and following return of malaria cases, DDT IRS was reintroduced in 2000 in Kwazulu Natal Province (IPEP, 2006). In Limpopo Province the DDT use was never stopped and subsequently most homesteads

\footnotetext{
* Corresponding author. Department of Zoology, D3LAB 343-B, University of Johannesburg, PO Box 524, Auckland Park, 2006, Johannesburg, South Africa. Tel.: + 27 11559 2620; fax: + 27115592286 .

E-mail address: cvandyk@uj.ac.za (J.C. Van Dyk).
}

within sprayed villages of the Vhembe District have been sprayed once per year since 1945 (Bornman et al., in press).

Because of the long half-lives of DDT and its metabolites, DDD and DDE (ATSDR, 2002), residues can persist for years within the DDTsprayed domestic environment. Through their daily activities in and around the house, residents could be exposed to DDT through a number of possible pathways including indoor air, floor dust, outdoor soil, food and water.

Where DDT has been applied in agriculture, ingestion via food has been recognised as the major pathway for human exposure (EHC 9, 1979; Tao et al., 2009). The uptake of pollutants by the roots of plants, as shown with DDT in rice by Chen et al. (2007), is often the first step in food chain accumulation (Kipopoulou et al., 1999). Vegetables of subsistence farmers in the Vhembe district might be contaminated with DDT by both root uptake from contaminated soil and spray-drift from DDT application during IRS. While vegetables make up a large portion of the diet of the VhaVenda people, poultry meat is a major source of protein. These animals have free range on the property including access to the DDT exposed floors inside the sprayed homesteads. DDT has been shown to accumulate in a number of chicken tissues including fat (Vazquez-Moreno et al., 1999), muscle (Aulakh et al., 2005) and liver (Tao et al., 2009). 
Despite its partial role as a direct route of exposure through inhalation, indoor air levels of DDT could also contribute significantly to the oral intake of DDT, through the precipitation of DDT particles on open food, water, and even eating utensils. In a study to determine the DDT residues in indoor air samples after DDT application for malaria vector control in India, Singh et al. (1991) found DDT residues in particulate phase in air up to 64 days after application. Similar results could therefore be expected in homesteads of the Vhembe district.

In addition to contaminated indoor air, soil and floor dust DDT levels within the domestic environment are of particular concern as children have longer exposure periods to outdoor soil and floor dust during play activities. A study by Vieira et al. (2001) found that after DDT application for sand-fly vector control in Rio de Janeiro, Brazil, soil samples still showed detectable levels of DDT nine years later. In another study, Herrera-Portugal et al. (2005) investigated environmental pathways of exposure to DDT for children living in a malariainfected area of Chiapas, Mexico. The study found that children living in a highly DDT-exposed area compared to a community less exposed to DDT, had higher serum levels of DDT and its metabolites, which corresponded with the DDT levels of both the indoor and outdoor soil levels, as well as indoor dust levels within their home environments.

Although the use of DDT has been credited with the successful elimination of malaria in a number of countries (Beard, 2006), due consideration should be given to the potential human health effects of exposure to DDT (Eskenazi et al., 2009). DDT IRS should therefore be carried out responsibly, to not only be effective in its objective, but also to ensure the safety of local communities regarding exposure to the pesticide. Although some studies have found little evidence for a link between DDT exposure and health effects, (Cocco et al., 2005, 2006), other studies have shown that DDT and its metabolites may have adverse health effects in humans (e.g. Beard, 2006; IPEP, 2006; Aneck-Hahn et al., 2006; Eskenazi et al., 2009). However, limited data is available on the levels of DDT exposure experienced by those living in sprayed homes. Also, it is not clear whether much of the DDT used for IRS is released into the surrounding environment (Longnecker, 2005). Investigating the DDT contamination levels of potential environmental pathways for human exposure within the domestic environment is therefore important. As advocated by Lioy (2006) and Sereda et al. (2009), the investigation of human exposure to indoor pollution should be done in the context of the Total Homestead Environment (THE) due to the implications of the dynamic and chemical processes associated with indoor environments concerning mixtures of chemicals. Therefore, all potential routes of exposure should be considered.

No comprehensive study has been done to determine the levels of DDT contamination in IRS homesteads in Africa. With the cooperation of the Malaria Control Programme of the Limpopo Province in South Africa, the current study aimed to assess the levels of DDT and its metabolites using a THE approach. This included the sampling of human serum, indoor air and floor dust, soil, water, vegetables, and chickens in rural villages of the Vhembe District in the Limpopo Province.

\section{Material and methods}

\subsection{Study area}

The study area is located within the Vhembe District $\left(21,000 \mathrm{~km}^{2}\right)$ in the Limpopo Province of South Africa. The area consists of large commercial farms including agriculture and forestry, but most of the region comprises of subsistence farming within different rural villages of the VhaVenda people. The central, northern and eastern parts of the district have been classified as an intermediate- to high-risk malaria region (DoH, 2005).

Two villages were selected for this study. The first, DV, was selected as the exposed village, located within the intermediate-risk malaria area where indoor DDT-spraying is done annually. The second,
TV, located approximately $23 \mathrm{~km}$ east from DV, outside the high-risk malaria area and never sprayed, was selected as the reference village.

\subsection{Sampling methodology}

Sampling was done in February 2008 during the summer season two months after the spray-team completed the IRS process in DV. Prior to the sampling period, the necessary ethical approvals were obtained from the Ethics Committee of the Faculty of Health Sciences of the University of Pretoria and the Department of Public Health of the Limpopo Province. In addition, the necessary permission was obtained from the local government and tribal authorities to conduct the study within the region. Four field workers from the local community were recruited to facilitate communication between the research team and the owners of the selected homesteads.

\subsubsection{Homestead selection}

Twelve homesteads were selected within the exposed village (D1-D12) and nine within the reference village (T1-T9). Care was taken to choose similar homesteads in terms of the traditional Venda architecture (these structures are usually not painted) as well as socio-economic status. A traditional Venda homestead is characterized by a number of round thatch-roof huts, 3-5 $\mathrm{m}$ in diameter, built in a compact circular arrangement. The walls consist of a mixture of mud and cement, and the floors consist of mud and/or cow manure or cement. The outdoor area between the huts is mainly open soil where children play, food is prepared on open fires, and chickens, goats and domestic pets roam free during the day. In most homesteads, the rest of the property is used for growing subsistence crops. These include, for the most part, leafy vegetables and maize. The crops are usually planted in close proximity $( \pm 1 \mathrm{~m})$ to the huts. Water for drinking, cooking, and bathing, is collected on a regular basis from either a centrally located community tap (borehole water), or from nearby natural springs. Water is usually stored on the property in large plastic containers before use. In DV, the nearby Luvuvhu River is also used by local residents for the washing of clothes as well as for swimming and bathing. With some variation, these conditions are typical of many rural areas in southern and eastern Africa.

\subsubsection{Sample collection and chemical analyses}

The following components of the domestic environment were sampled for DDT residue analyses: human serum; indoor air and floor dust; outdoor soil; leafy vegetables; potable water; as well as chicken fat, liver and muscle tissue. All samples were analyzed for DDT and its metabolites DDD and DDE for both $o, p^{\prime}$ - and $p, p^{\prime}$-isomers. Three laboratories were used as they were GLP (Good Laboratory Practice) accredited for different sample matrixes.

2.2.2.1. Human serum. Blood samples were collected at each homestead from all willing participants, 18 years and older, living on the property ( $D V n=19 ;$ TV $n=3$ ). Only three residents from two homesteads in TV, (two males aged 30 and 32, and a female age 65) were willing to donate blood as residents from the remaining homesteads declined due to traditional beliefs associated with blood. An informed consent form and a questionnaire on related dietary information were completed and signed by each participant. Interviews were conducted in the local language (TsiVenda) with the assistance of the recruited fieldworkers. Blood samples ( $\pm 14 \mathrm{~mL}$ per participant) were collected by a certified medical practitioner from the University of Pretoria, centrifuged at 30,000 rpm, and serum samples were stored at $-20^{\circ} \mathrm{C}$ until chemical analyses. Total cholesterol and triglyceride levels were determined by AMPATH National Laboratory Support Services (Pretoria, South Africa). Total serum lipids (TL) were calculated according to the methodology by Philips et al. (1989). Limit of detection was $5.0 \mu \mathrm{g} \mathrm{L}^{-1}$. 
Lipid adjusted DDT levels were calculated as the total DDT residue level divided by the TL. The participants from DV ranged in age between 20 and 88 years, included three male and 16 female participants of whom nine were unemployed, eight were pensioners; 15 of these participants have lived at their current address for more than 10 years. Two of the participants have been infected with malaria before.

2.2.2.2. Indoor air and floor dust. Indoor air and floor dust were sampled in one hut from each homestead. Floor dust samples were collected over a surface area of $1247 \mathrm{~cm}^{2}$ near the DDT-treated walls using vacuum suction. The dust samples were trapped on $5 \mathrm{~cm}$ diameter glass micro-fibre filters (GMF) (Whatman) (Kent, UK) Sampling blanks were collected at random time intervals. The GMF were fitted onto a specially manufactured, spring loaded, aluminium vacuum suction manifold which was connected to a suction pump. After sampling, the GMF were placed in aluminium foil, labelled, and stored in sealed plastic bags.

Airborne DDT residues were measured using a high volume monitoring procedure. DDT residues were collected on two serially fitted $5 \mathrm{~cm} \times 6 \mathrm{~cm}$ high density polyurethane foam discs (PUF). The PUFs were pre-fitted into $5 \mathrm{~cm} \times 14 \mathrm{~cm}$ aluminium cartridges, supported by an expanded aluminium mesh. The PUF sampling filters were washed three times with hexane before use. Each sampling cartridge was connected to a common sampling manifold using $5 \mathrm{~cm}$ inner diameter vacuum tubing. A single sampling cartridge was used to sample the ambient air in each hut. The PUF samples were sealed in aluminium foil, labelled and stored in plastic bags before analyses. PUF samples were collected at $350-400 \mathrm{~L} \mathrm{~min}^{-1}$ for a period of $30 \mathrm{~min}$. The air flow-rate and duration of air sampling was used to calculate the final air volume sampled.

2.2.2.3. Outdoor soil. Five soil samples were collected per homestead at five different areas on the property close to the sprayed huts. Each sample, $50 \mathrm{~cm} \times 50 \mathrm{~cm} \times 5 \mathrm{~cm}$ (d) was collected in a brown paper bag, sealed, and kept at room temperature until chemical analyses. The methodology used is based on the method by Naudé et al. (1998). A $100 \mathrm{~mL}$ of Hexane-petroleum ether $(50: 50, \mathrm{v} / \mathrm{v})$ was added to $5 \mathrm{~g}$ of each sample, followed by Soxhlet extraction for $12 \mathrm{~h}$. SPE cleanup of cooled samples was performed on C18 cartridges. Limit of detection was $0.5 \mu \mathrm{gg}^{-1}$.

2.2.2.4. Potable water. One $2500 \mathrm{~mL}$ sample of drinking water was collected per homestead in pre-cleaned glass bottles. Each bottle was sealed and stored at $\pm 15{ }^{\circ} \mathrm{C}$ until chemical analyses. In addition, a water sample was also collected directly from the community tap in DV, and from the nearby Luvuvhu River. DDT residue analyses were done based on the method by Cacho et al. (1995). A $1000 \mathrm{~mL}$ volume of each water sample was filtered into an acid washed reagent bottle. Solid phase $\mathrm{C} 18$ cartridges (Waters-Microsep) were conditioned with methanol and water. The cartridges were dried and eluted with $12 \mathrm{~mL}$ of hexane-diethylether $(85: 15, \mathrm{v} / \mathrm{v})$. The extracts were evaporated under nitrogen to dryness and reconstituted in $200 \mu \mathrm{L}$ methanol. Limit of detection was $0.5 \mu \mathrm{g} \mathrm{L}{ }^{-1}$.

2.2.2.5. Leafy vegetables. A composite sample of three types of leafy vegetables was collected per homestead. Leaves were sampled from crops surrounding the huts on the property. Samples were collected in brown paper bags and stored at $-20{ }^{\circ} \mathrm{C}$ until chemical analyses. Extraction was done with acetonitrile extraction/partitioning and dispersive solid-phase extraction clean-up, based on the QuECHERS method (Anastassiades et al., 2003). Limit of detection was $10.0 \mu \mathrm{g} \mathrm{kg}^{-1}$

2.2.2.6. Chickens. One chicken was collected per homestead, or, if not available, from a neighbour or nearby homestead. The owner of the chicken was financially compensated. The chickens were killed and muscle, fat, and liver samples were collected. Each sample was individually stored in aluminium foil at $-20{ }^{\circ} \mathrm{C}$ until chemical analyses. The methodology used is based on the method by Bordet et al. (2002). Solid phase C18 cartridges (Waters-Microsep) were conditioned with $5 \mathrm{~mL}$ of petroleum ether, acetone and methanol sequentially. The samples were reconstituted into $250 \mu \mathrm{L}$ hexane for analysis. Limit of detection was $50.0 \mu \mathrm{g} \mathrm{kg}^{-1}$.

For each of the matrices (excluding human serum as indicated above), samples were collected at 12 homesteads in DV, and nine homesteads in TV. Indoor air and floor dust samples were collected and analysed by the Agricultural Research Council's Plant Protection Research Institute of South Africa (ARC-PPRI) using capillary gas chromatography with electron capture detection (GC-ECD). Human serum, soil, water, and chicken samples were analyzed by FDA laboratories (Pretoria, South Africa), and vegetable DDT residue analyses were done by the South African Bureau of Standards (SABS) using gas chromatography-mass spectrometry (GC-MS).

\subsection{Statistical analyses}

The results of the chemical analyses are presented for all six isomers of DDT as well as the total DDT - the sum of all isomers ( $\sum$ DDT) - detected per sample. Associations between the data from the reference and the exposed villages were calculated using a twotailed $t$-test using STATA10. The level of significance was set at $5 \%$. To explore associations between the six different DDT isomers and the different matrixes sampled in the domestic environment, multivariate analysis was done by Non-metric Multidimensional Scaling (NMS) using PC-ORD 4. NMS avoids the assumption of linear relationships among variables by using ranked distances to linearize the relationships between measured distances between individual sample points in a multidimensional ordination space, and accommodates minima (absence, or 0 for $<\mathrm{LOQ}$ ) better than other ordination methods (McCune and Grace, 2002). The distance measure used was relative Euclidian (see McCune and Grace, 2002 for discussion on distance measures). Data were relativized across columns to investigate DDT isomer profiles using relative proportions of the pollutants rather than absolute values. Three dimensions were derived but only the two strongest axes will be presented. The closer individual sample points are located to each other the greater their profile similarity; samples with a high proportion of $p, p^{\prime}$-DDT for instance would cluster closer together. The angle and length of the vectors indicate the direction and strength of that variable. Random starting configurations were used with 50 runs of real data. We used 50 runs of randomised data for Monte Carlo tests. Final stress can be interpreted as follows: $<5$ excellent, 5-10 good, 10-20 general picture good, but not in detail, $>20$ not good (McCune and Grace, 2002).

\section{Results}

Results of analysis are summarised in Table 1. DV had the most samples with detectable levels of DDT and its metabolites, and with the exception of chicken muscle samples, DV also had higher mean levels for all the components analyzed compared to TV. 79\% of participants from DV had detectable levels of $\Sigma$ DDT of which the $p, p^{\prime}$-DDE levels was the highest. Of the three serum samples from TV, only one participant had a detectable level of $p, p^{\prime}$-DDE.

Both Indoor air and dust samples had significantly higher levels of $\sum$ DDT $(P<0.05)$ in DV compared to TV. In both these media, $p, p^{\prime}$-DDT was the main metabolite present. Regarding the outdoor components, soil and vegetable samples had higher levels of $\Sigma$ DDT compared to water samples. Although the relative number of samples with detectable levels in outdoor soil was higher in DV compared to TV, the individual sample with the highest value was from a homestead in TV. In both villages, the $\Sigma$ DDT in outdoor soil constituted mainly of $p, p^{\prime}$-DDE whereas vegetable samples were mainly contaminated with 


\section{Table 1}

Summary of DDT concentrations detected in human serum, indoor air, floor dust, outside soil, potable water, vegetable, and chicken samples from the exposed (DV) and control village (TV).

\begin{tabular}{|c|c|c|c|c|c|c|c|c|c|c|c|c|c|c|c|}
\hline & $\sum \mathrm{DDT}$ & $p, p^{\prime}$-DDT & $o, p^{\prime}$-DDT & $p, p^{\prime}-\mathrm{DDD}$ & $o, p^{\prime}-\mathrm{DDD}$ & $p, p^{\prime}$-DDE & $0, p^{\prime}-\mathrm{DDE}$ & & $\sum \mathrm{DDT}$ & $p, p^{\prime}$-DDT & $o, p^{\prime}$-DDT & $p, p^{\prime}$-DDD & $o, p^{\prime}-\mathrm{DDD}$ & $p, p^{\prime}$-DDE & $o, p^{\prime}-\mathrm{DDE}$ \\
\hline \multicolumn{8}{|c|}{ Human serum: DV ( $n=19)\left(\mu \mathrm{g} \mathrm{g}^{-1}\right.$ lipid $)$} & \multicolumn{8}{|c|}{ Potable water $\left({ }^{*}\right): \mathrm{DV}(n=12)\left(\mu \mathrm{g} \mathrm{L}^{-1}\right)$} \\
\hline Mean & 7.3 & $\mathrm{n} / \mathrm{d}$ & $\mathrm{n} / \mathrm{d}$ & 1.5 & 1.5 & 5.9 & $\mathrm{n} / \mathrm{d}$ & Mean & 2.0 & 0.8 & 0.7 & $\mathrm{n} / \mathrm{d}$ & $\mathrm{n} / \mathrm{d}$ & 1.2 & $\mathrm{n} / \mathrm{d}$ \\
\hline SD & 6.7 & $\mathrm{n} / \mathrm{d}$ & $\mathrm{n} / \mathrm{d}$ & 1.1 & 1.7 & 5.5 & $\mathrm{n} / \mathrm{d}$ & SD & 2.1 & 0.1 & 0.1 & $\mathrm{n} / \mathrm{d}$ & $\mathrm{n} / \mathrm{d}$ & 0.7 & $\mathrm{n} / \mathrm{d}$ \\
\hline Median & 5.1 & $\mathrm{n} / \mathrm{d}$ & $\mathrm{n} / \mathrm{d}$ & 1.1 & 1.5 & 4.7 & $\mathrm{n} / \mathrm{d}$ & Median & 0.9 & 0.8 & 0.7 & $\mathrm{n} / \mathrm{d}$ & $\mathrm{n} / \mathrm{d}$ & 1.0 & $\mathrm{n} / \mathrm{d}$ \\
\hline Min-Max & $1.3-23$ & 1.4 & 2.4 & $0.8-3.8$ & $0.3-2.7$ & $1.2-23$ & 22 & Min-Max & $0.6-7.6$ & $0.8-1.0$ & $0.6-0.8$ & 1.8 & 1.1 & $0.7-2.0$ & 1.1 \\
\hline NumPos & 15 & 1 & 1 & 6 & 2 & 15 & 1 & NumPos & 10 & 8 & 5 & 1 & 1 & 3 & 1 \\
\hline \multicolumn{8}{|c|}{ Human serum: TV ( $n=3)\left(\mu \mathrm{g} \mathrm{g}^{-1}\right.$ lipid $)$} & \multicolumn{8}{|c|}{ Vegetables $\left({ }^{*}\right)$ : DV $(n=12)\left(\mu \mathrm{kg}^{-1}\right)$} \\
\hline Mean & $\mathrm{n} / \mathrm{d}$ & $\mathrm{n} / \mathrm{d}$ & $\mathrm{n} / \mathrm{d}$ & $\mathrm{n} / \mathrm{d}$ & $\mathrm{n} / \mathrm{d}$ & $\mathrm{n} / \mathrm{d}$ & $\mathrm{n} / \mathrm{d}$ & Mean & 43 & 70 & $\mathrm{n} / \mathrm{d}$ & 32 & $\mathrm{n} / \mathrm{d}$ & 10 & $\mathrm{n} / \mathrm{d}$ \\
\hline SD & $\mathrm{n} / \mathrm{d}$ & $\mathrm{n} / \mathrm{d}$ & $\mathrm{n} / \mathrm{d}$ & $\mathrm{n} / \mathrm{d}$ & $\mathrm{n} / \mathrm{d}$ & $\mathrm{n} / \mathrm{d}$ & $\mathrm{n} / \mathrm{d}$ & SD & 45 & 14 & $\mathrm{n} / \mathrm{d}$ & 22 & $\mathrm{n} / \mathrm{d}$ & 0.0 & $\mathrm{n} / \mathrm{d}$ \\
\hline Median & $\mathrm{n} / \mathrm{d}$ & $\mathrm{n} / \mathrm{d}$ & $\mathrm{n} / \mathrm{d}$ & $\mathrm{n} / \mathrm{d}$ & $\mathrm{n} / \mathrm{d}$ & $\mathrm{n} / \mathrm{d}$ & $\mathrm{n} / \mathrm{d}$ & Median & 25 & 70 & $\mathrm{n} / \mathrm{d}$ & 30 & $\mathrm{n} / \mathrm{d}$ & 10 & $\mathrm{n} / \mathrm{d}$ \\
\hline Min-Max & 2.1 & $\mathrm{n} / \mathrm{d}$ & $\mathrm{n} / \mathrm{d}$ & $\mathrm{n} / \mathrm{d}$ & $\mathrm{n} / \mathrm{d}$ & 2.1 & $\mathrm{n} / \mathrm{d}$ & Min-Max & $10-150$ & $60-80$ & $\mathrm{n} / \mathrm{d}$ & $10-80$ & $\mathrm{n} / \mathrm{d}$ & $10-10$ & $\mathrm{n} / \mathrm{d}$ \\
\hline NumPos & 1 & 0 & 0 & 0 & 0 & 1 & 0 & NumPos & 11 & 2 & 0 & 11 & 0 & 2 & 0 \\
\hline \multicolumn{8}{|c|}{ Indoor air: DV $(n=12)\left(\mathrm{ng} \mathrm{m}^{-3}\right)$} & \multicolumn{8}{|c|}{ Chicken muscle: DV $(n=12)\left(\mu \mathrm{kg}^{-1}\right)$} \\
\hline Mean & 3900 & 2200 & 1400 & 91 & 50 & 110 & 27 & Mean & 500 & 130 & 55 & 91 & $\mathrm{n} / \mathrm{d}$ & 290 & 53 \\
\hline SD & 2700 & 1500 & 1500 & 45 & 41 & 110 & 27 & SD & 400 & 100 & 1.5 & 15 & $\mathrm{n} / \mathrm{d}$ & 230 & 2.1 \\
\hline Median & 2700 & 1800 & 670 & 84 & 33 & 71 & 20 & Median & 290 & 79 & 55 & 99 & $\mathrm{n} / \mathrm{d}$ & 210 & 53 \\
\hline Min-Max & $1100-8800$ & $750-6000$ & $270-5300$ & $43-190$ & $16-150$ & $23-390$ & $4.6-89$ & Min-Max & $69-1400$ & $53-330$ & $53-56$ & $73-100$ & $\mathrm{n} / \mathrm{d}$ & $92-840$ & $51-54$ \\
\hline NumPos & 12 & 12 & 12 & 12 & 12 & 12 & 11 & \multirow{2}{*}{\multicolumn{8}{|c|}{$\begin{array}{l}\text { NumPos } \\
\text { Chicken muscle: } \operatorname{TV}(n=9)\left(\mu \mathrm{g} \mathrm{kg}^{-1}\right)\end{array}$}} \\
\hline \multicolumn{8}{|c|}{ Indoor air: $\operatorname{TV}(n=9)\left(\mathrm{ng} \mathrm{m}^{-3}\right)$} & & & & & & & & \\
\hline Mean & 10 & 7.2 & 4.8 & $\mathrm{n} / \mathrm{d}$ & 2.2 & $\mathrm{n} / \mathrm{d}$ & $\mathrm{n} / \mathrm{d}$ & Mean & 700 & 130 & $\mathrm{n} / \mathrm{d}$ & $\mathrm{n} / \mathrm{d}$ & $\mathrm{n} / \mathrm{d}$ & 540 & $\mathrm{n} / \mathrm{d}$ \\
\hline SD & 13 & 8.9 & 5.1 & $\mathrm{n} / \mathrm{d}$ & 0.8 & $\mathrm{n} / \mathrm{d}$ & $\mathrm{n} / \mathrm{d}$ & SD & 940 & 110 & $\mathrm{n} / \mathrm{d}$ & $\mathrm{n} / \mathrm{d}$ & $\mathrm{n} / \mathrm{d}$ & 780 & $\mathrm{n} / \mathrm{d}$ \\
\hline Median & 13 & 8.9 & 5.0 & $\mathrm{n} / \mathrm{d}$ & 1.0 & $\mathrm{n} / \mathrm{d}$ & $\mathrm{n} / \mathrm{d}$ & Median & 290 & 80 & $\mathrm{n} / \mathrm{d}$ & $\mathrm{n} / \mathrm{d}$ & $\mathrm{n} / \mathrm{d}$ & 180 & $\mathrm{n} / \mathrm{d}$ \\
\hline Min-Max & $1.5-41$ & $1.5-28$ & $0.7-13$ & $\mathrm{n} / \mathrm{d}$ & $1.6-2.7$ & $\mathrm{n} / \mathrm{d}$ & $\mathrm{n} / \mathrm{d}$ & Min-Max & $190-2100$ & $52-80$ & 55 & 79 & 60 & $89-1700$ & 54 \\
\hline NumPos & 9 & 8 & 5 & 0 & 2 & 0 & 0 & NumPos & 4 & 3 & 1 & 1 & 1 & 4 & 1 \\
\hline \multicolumn{8}{|c|}{ Floor dust: $\mathrm{DV}(n=12)\left(\mathrm{ug} \mathrm{m}^{-2}\right)$} & \multicolumn{8}{|c|}{ Chicken fat: DV $(n=12)\left(\mu \mathrm{g} \mathrm{kg}^{-1}\right)$} \\
\hline Mean & 1200 & 1100 & 100 & 25 & 7.9 & 51 & $\mathrm{n} / \mathrm{d}$ & Mean & 240,000 & 41,000 & 410 & 3000 & 100 & 190,000 & 97 \\
\hline SD & 1500 & 1300 & 120 & 20 & 1.7 & 85 & $\mathrm{n} / \mathrm{d}$ & SD & 380,000 & 28,000 & 170 & 1200 & 67 & 360,000 & 53 \\
\hline Median & 910 & 850 & 57 & 18 & 7.5 & 22 & $\mathrm{n} / \mathrm{d}$ & Median & 150,000 & 45,000 & 380 & 3500 & 72 & 87,000 & 72 \\
\hline Min-Max & $8.3-4800$ & $8.3-4200$ & $6.5-230$ & $7.5-71$ & $6.4-9.8$ & $8.5-260$ & 34 & Min-Max & $320-1,300,000$ & $68-77,000$ & $140-610$ & $330-4200$ & $58-200$ & $250-1,200,000$ & $58-210$ \\
\hline NumPos & 12 & 12 & 10 & 10 & 3 & 8 & 1 & NumPos & 10 & 10 & 9 & 9 & 4 & 10 & 8 \\
\hline \multicolumn{8}{|c|}{ Floor dust: $\operatorname{TV}(n=9)\left(\mu \mathrm{g} \mathrm{m}^{-2}\right)$} & \multicolumn{8}{|c|}{ Chicken fat: TV $(n=9)\left({\left.\mu \mathrm{g} \mathrm{kg}^{-1}\right)}\right.$} \\
\hline Mean & 1.8 & 1.5 & 0.3 & 0.1 & 0.1 & 0.1 & $\mathrm{n} / \mathrm{d}$ & Mean & 540 & 440 & 54 & $\mathrm{n} / \mathrm{d}$ & $\mathrm{n} / \mathrm{d}$ & 190 & 58 \\
\hline SD & 2.9 & 2.5 & 0.4 & 0.0 & 0.0 & 0.0 & $\mathrm{n} / \mathrm{d}$ & SD & 740 & 760 & 4.2 & $\mathrm{n} / \mathrm{d}$ & $\mathrm{n} / \mathrm{d}$ & 170 & 9.2 \\
\hline Median & 1.3 & 1.0 & 0.2 & 0.0 & 0.0 & 0.0 & $\mathrm{n} / \mathrm{d}$ & Median & 170 & 78 & 54 & $\mathrm{n} / \mathrm{d}$ & $\mathrm{n} / \mathrm{d}$ & 120 & 58 \\
\hline Min-Max & $0.1-8.9$ & $0.1-7.6$ & $0.1-0.5$ & $0.1-0.1$ & $0.1-0.1$ & $0.1-0.1$ & $\mathrm{n} / \mathrm{d}$ & Min-Max & 99-2100 & $52-1800$ & $51-57$ & 65 & $\mathrm{n} / \mathrm{d}$ & $74-550$ & $51-64$ \\
\hline NumPos & 9 & 9 & 6 & 3 & 2 & 2 & 0 & NumPos & 7 & 5 & 2 & 1 & 0 & 7 & 2 \\
\hline \multicolumn{8}{|c|}{ Outside soil: DV $(n=12)\left(\mu \mathrm{kg}^{-1}\right)$} & \multicolumn{8}{|c|}{ Chicken liver: DV $(n=12)\left(\mu \mathrm{kg}^{-1}\right)$} \\
\hline Mean & 25 & 1.0 & 0.7 & 4.1 & 1.0 & 16 & 3.5 & Mean & 1600 & 220 & 59 & 270 & $\mathrm{n} / \mathrm{d}$ & 1200 & $\mathrm{n} / \mathrm{d}$ \\
\hline SD & 18 & 0.2 & 0.1 & 8.2 & 0.4 & 16 & 1.6 & SD & 1500 & 190 & 10 & 150 & $\mathrm{n} / \mathrm{d}$ & 1300 & $\mathrm{n} / \mathrm{d}$ \\
\hline Median & 20 & 0.9 & 0.7 & 1.7 & 1.0 & 9.1 & 3.2 & Median & 1100 & 190 & 54 & 230 & $\mathrm{n} / \mathrm{d}$ & 780 & $\mathrm{n} / \mathrm{d}$ \\
\hline Min-Max & $5.7-59$ & $0.8-1.2$ & $0.6-0.9$ & $0.6-30$ & $0.6-1.7$ & $3.0-47$ & $1.7-6.2$ & Min-Max & $52-5600$ & $50-600$ & $52-78$ & $130-540$ & $\mathrm{n} / \mathrm{d}$ & $52-4700$ & $\mathrm{n} / \mathrm{d}$ \\
\hline NumPos & 12 & 12 & 12 & 12 & 9 & 12 & 10 & NumPos & 12 & 9 & 6 & 10 & 0 & 12 & 0 \\
\hline \multicolumn{8}{|c|}{ Outside soil: TV $(n=9)\left(\mu \mathrm{kg}^{-1}\right)$} & \multicolumn{8}{|c|}{ Chicken liver: $\operatorname{TV}(n=9)\left(\mu \mathrm{g} \mathrm{kg}^{-1}\right)$} \\
\hline Mean & 21 & 1.4 & 1.0 & 2.9 & 2.2 & 14 & 6.8 & Mean & 160 & $\mathrm{n} / \mathrm{d}$ & $\mathrm{n} / \mathrm{d}$ & $\mathrm{n} / \mathrm{d}$ & 61 & $\mathrm{n} / \mathrm{d}$ & $\mathrm{n} / \mathrm{d}$ \\
\hline SD & 36 & 1.2 & 0.7 & 1.7 & 2.0 & 28 & 4.0 & SD & 190 & $\mathrm{n} / \mathrm{d}$ & $\mathrm{n} / \mathrm{d}$ & $\mathrm{n} / \mathrm{d}$ & 8 & $\mathrm{n} / \mathrm{d}$ & $\mathrm{n} / \mathrm{d}$ \\
\hline Median & 5.5 & 0.8 & 0.6 & 3.4 & 1.3 & 3.1 & 6.8 & Median & 65 & $\mathrm{n} / \mathrm{d}$ & $\mathrm{n} / \mathrm{d}$ & $\mathrm{n} / \mathrm{d}$ & 60 & $\mathrm{n} / \mathrm{d}$ & $\mathrm{n} / \mathrm{d}$ \\
\hline Min-Max & $2.1-93$ & $0.8-3.5$ & $0.6-2.3$ & $1.0-4.2$ & $0.8-4.5$ & $0.7-72$ & $4.0-9.6$ & Min-Max & $54-440$ & 63 & 53 & $\mathrm{n} / \mathrm{d}$ & $54-70$ & 320 & $\mathrm{n} / \mathrm{d}$ \\
\hline NumPos & 6 & 5 & 5 & 3 & 3 & 6 & 2 & NumPos & 4 & 1 & 1 & 0 & 3 & 1 & 0 \\
\hline
\end{tabular}

$\mathrm{SD}=$ Standard deviation; NumPos $=$ Number of positive samples ( $>$ detection limit); $\mathrm{n} / \mathrm{d}=$ not detected.

$\left(^{*}\right)$ Potable water and vegetable sample results for TV are not included in the table as no samples had levels above the detection limit. 
$p, p^{\prime}$-DDT and $p, p^{\prime}$-DDD. In DV, 83\% of water samples had levels of $o, p^{\prime}$ and $p, p^{\prime}$-DDT as well as $p, p^{\prime}$-DDE. The water samples from TV had no detectable levels of DDT or its metabolites. Comparing the different chicken tissue samples, fat had the highest levels of DDT, DDD and DDE compared to liver and muscle samples in both DV and TV. In all three tissue types, $p, p^{\prime}$-DDE were predominant.

Fig. 1 shows the NMS joint plot for DV. The distance between the points (samples) is approximately proportional to the dissimilarities between them. Three dimensions were derived. The final stress was 7.85 reached after 200 iterations. Final stress can be interpreted as follows: $<5$ excellent, 5-10 good, 10-20 general picture good, but not in detail, $>20$ not good (McCune and Grace, 2002). Final instability was 0.016 . The Monte Carlo tests were significant for Axis 1 and 2 $(P<0.05)$. Axis 2 explained $6.6 \%$ of the variation, and Axis 3, 59\%, for a cumulative explanation of $56.6 \%$, and adjusted cumulative of $99.8 \%$. Fig. 2 shows the NMS joint plot for TV. Three dimensions were derived with a final stress of 19.9 reached after 200 iterations, and a final instability of 0.0039. The Monte Carlo tests were significant for Axis 1 and $2(P<0.05)$. Axis 1 explained $40 \%$ of the variation, and Axis $2,34 \%$, for a cumulative explanation of $74 \%$, and adjusted cumulative of $92 \%$.

The multivariate analysis showed a clear association between indoor air and floor dust samples and $p, p^{\prime}$-DDT levels in both DV and TV (Figs. 1 and 2). In DV, chicken samples and human serum samples were mainly associated with $p, p^{\prime}$-DDE levels while the metabolites $p, p^{\prime}$-DDD, $o, p^{\prime}$-DDE and $p, p^{\prime}$-DDE were associated with the outdoor soil samples. No associations were found between either the water or vegetable samples and DDT specifically, or one of its metabolites respectively.

\section{Discussion}

The results show that the domestic environment of homesteads in the Vhembe district is contaminated with DDT, and that residents are exposed to DDT and its metabolites through a number of ways including contaminated indoor air, floor dust, outdoor soil, food, and water. Considering that the DDT $75 \%$ water wettable powder formulation applied during IRS consist mainly of the $p, p^{\prime}$ - and $o, p^{\prime}$-DDT, isomers (73\% p, $p^{\prime}$-DDT and 22\% o, $p^{\prime}$-DDT of the active ingredient) (Bouwman et al., 2006), it was expected that a similar profile would be detected in the various components within the total homestead environment. However, various factors should be considered regarding the different $\Sigma$ DDT profile in the different components sampled: (1) rate of metabolization of DDT to DDD and DDE in different substrates, (2) exposure to DDD and DDE already present in the environment, (3) the capacity of the different metabolites to be accumulated and be stored in different environmental components.

\subsection{Human serum}

EDDT serum levels varied among participants from DV (84\% female/16\% male). The sample group ranged between ages 20 and 88 years. This could explain the variation in $\sum$ DDT serum levels, as the statistical analyses showed a positive correlation between the $\sum$ DDT levels and the age of the participants. The $\sum$ DDT in all participants constituted mainly $p, p^{\prime}$-DDE and $p, p^{\prime}$-DDD. The multivariate analysis also showed a strong association between DDE and human serum (Fig. 1). As the breakdown products of DDT, these metabolites could be indicative of prior exposure to the pesticide. The questionnaires indicated that $79 \%$ of the participants have lived within the sprayed area for more than 10 years, confirming long-term exposure to DDT of most of the participants in the sample group. The higher serum DDE levels detected in participants from DV is therefore either the result of their own metabolism of DDT over the exposure period, or from ingestion of DDE present in their food or from exposure to DDE present in the surrounding environment (Longnecker, 2005; Sereda et al., 2009).

Compared to a previous study, the mean $p, p^{\prime}$-DDE level of $27 \mu \mathrm{g} \mathrm{L}{ }^{-1}$ (not lipid adjusted) measured in the serum of participants from DV

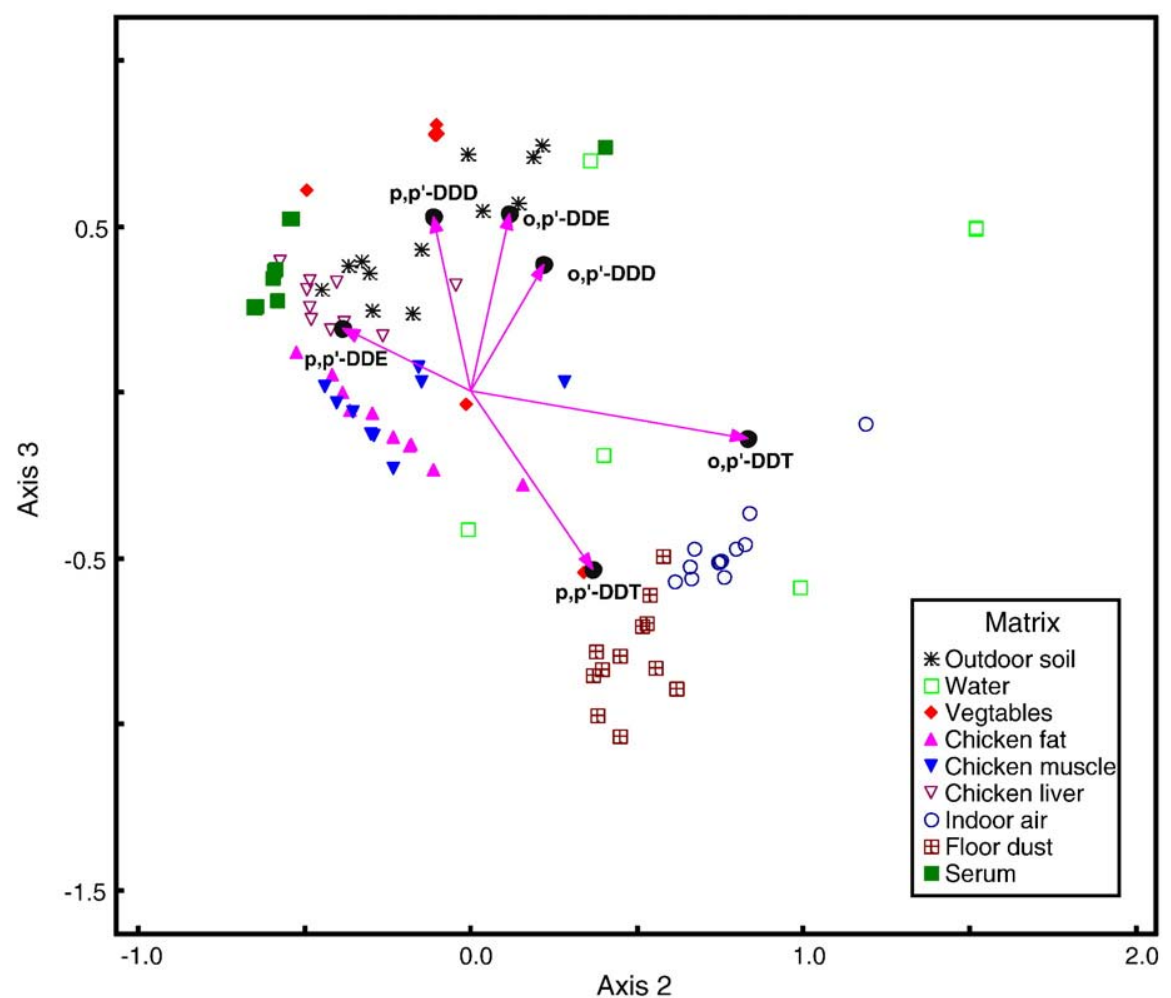

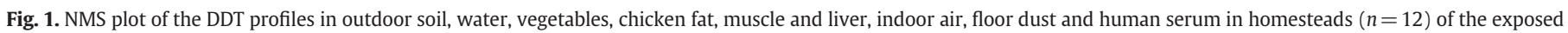
village (DV). 


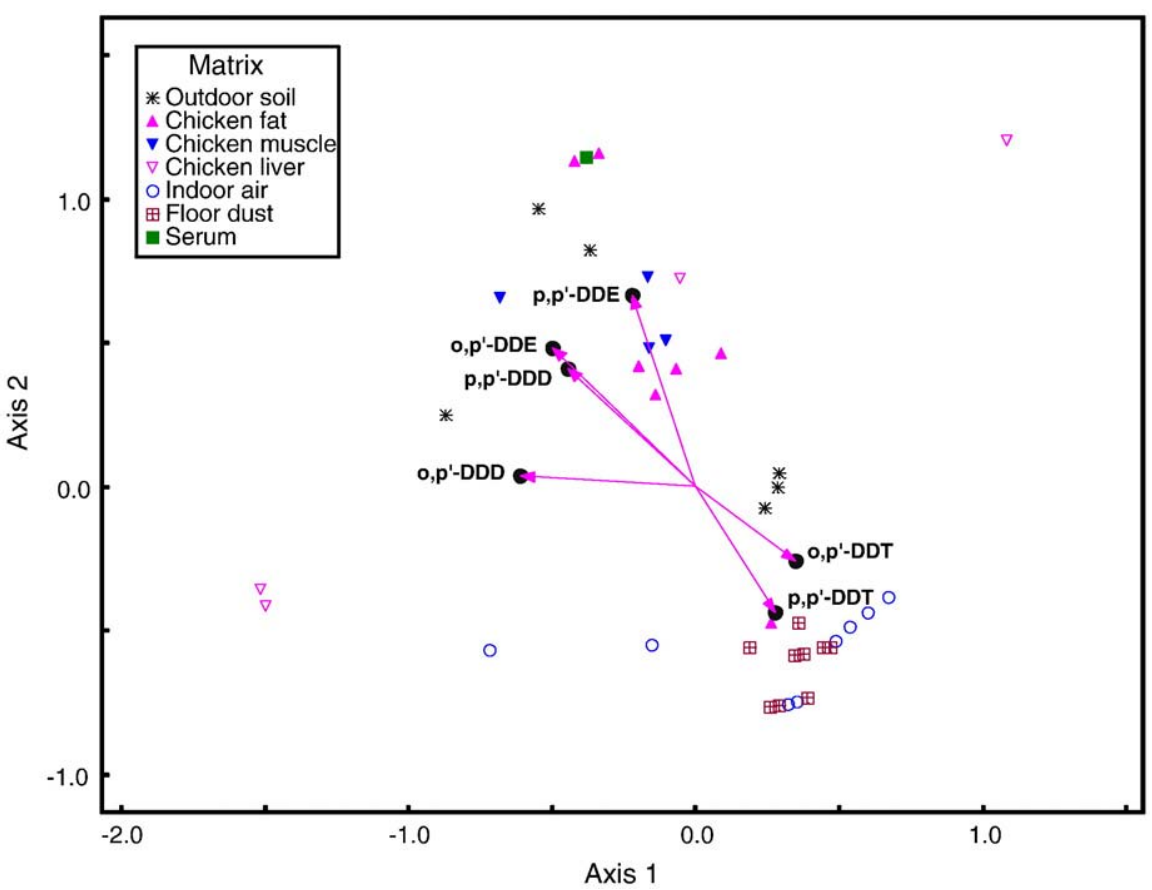

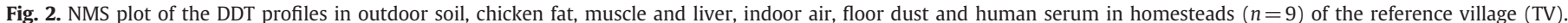

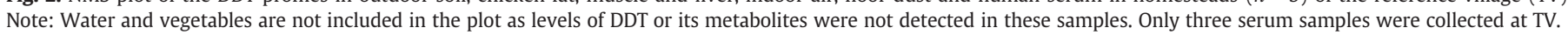

falls within the range detected in adults living in two DDT-sprayed malarious communities in Mexico: Chiapas (24.9-138.8 $\left.\mu \mathrm{g} \mathrm{L}^{-1}\right)$ and Oaxaca (5.7-97.7 $\mu \mathrm{g} \mathrm{L}^{-1}$ )(Yáňez et al., 2002). Compared to the reference village in the current study, no statistical comparison could be made as only three participants from the nine homesteads in TV were willing to donate blood. The serum of two of these three participants had no levels of DDT and/or its metabolites and one participant had a detectable level of DDE. Yet the serum DDE level of this participant was below the mean DDE value calculated for the exposed village. Even so, levels of DDT in residents from the reference village are not unexpected as a number of factors could contribute to the DDT exposure of residents of nearby, unsprayed areas. Some of the factors may include travelling between the sprayed and unsprayed villages, airborne movement of DDT, illegal use of the pesticide for purposes other than vector control outside the malaria risk area, and the distribution of contaminated food throughout the Vhembe district. It is reasonable, however, to expect that residents in exposed villages would have higher levels of DDT compared to unexposed villages. Bouwman et al. (1991) also found that serum levels of residents of DDT-sprayed dwellings in Kwazulu Natal, South Africa, had significantly higher $(P<0.05)$ levels of $\sum$ DDT (mean: $140.9 \mu \mathrm{g} \mathrm{L}^{-1}$ ) compared to an unexposed area (mean: $6.04 \mu \mathrm{g} \mathrm{L}^{-1}$ ). In this case however, the reference village was located approximately $500 \mathrm{~km}$ away from the nearest malaria control area.

The serum analyses results of participants from DV are noteworthy as a number of studies have shown associations between DDT and/or its metabolites, and human health effects. $p, p^{\prime}$-DDT, an estrogenic endocrine disrupting chemical, and its anti-androgenic metabolite, $p, p^{\prime}$-DDE, have been linked to male reproductive health effects (De Jager et al., 2006; Aneck-Hahn et al., 2006). DDT and/or DDE have also been linked with post generational female reproductive ability (Cohn et al., 2003), urogenital birth defects in neonates (Bornman et al., 2005) and pre-term births (Longnecker et al., 2001). In addition to neurological effects as indicated by the ATSDR (2002), McGlynn et al. (2006) also found that high DDT serum levels may be a risk factor for liver cancer. However, no statistically significant association between liver cancer and serum DDE concentrations were found.

\subsection{Indoor air}

The DDT residue analyses of the air samples indicated that measurable levels of DDT, DDD, and DDE are still present in the indoor air of the sprayed huts 84 days after the spraying was completed. However, the multivariate analyses showed the strongest association between the indoor air samples and $p, p^{\prime}$-DDT (Fig. 1). This is not unexpected as the formulation of applied DDT constituted $~ 73 \%$ $p, p^{\prime}$-DDT (Bouwman et al., 2006). Although low levels of DDT were also detected in the air samples of the reference village, the levels in DV were significantly higher $(P<0.05)$. The indoor air $\Sigma$ DDT levels detected in DV (median: $2700 \mathrm{ng} \mathrm{m}^{-3}$ ) are also considerably higher than the EPA inhalation unit risk of $0.097 \mathrm{ng} \mathrm{m}^{-3}$ (ATSDR, 2002). The levels measured in the current study also corresponds with a study by Singh et al. (1991), who reported that during an eight month sampling period, the indoor air samples from homes sprayed with DDT in India had DDT levels ranging between 1000-14600 $\mathrm{ng} \mathrm{m}^{-3}$. Exposure through inhalation could be restricted due to the large particle size $(\geq 250 \mu \mathrm{m})$ of DDT. However, as the DDT particles are deposited in the upper respiratory tract, it is eventually swallowed (Hayes, 1975), and together with the precipitation of the DDT spray on open food and water within the homes, could ultimately contribute to the total amount of DDT ingested. The residues in the indoor air samples measured in DV are also likely to contribute to the contamination of the surrounding environmental media as it disperses into the ecosystem (Singh et al., 1991).

\subsection{Floor dust and outdoor soil}

The presence of DDT and its metabolites in the floor dust samples were significantly higher $(P<0.05)$ in DV compared to TV. Both outdoor soil and floor dust samples from DV were highly contaminated with DDT, DDD and DDE. However, similarly to the indoor air samples, the multivariate analyses showed the strongest association between the floor dust samples and $p, p^{\prime}$-DDT - probably as a results of the deposition of DDT in indoor air particles - while the strongest association with outdoor soil was with DDD and DDE (Fig. 1). The 
results raise concerns regarding human exposure to the contaminated soil and dust, and in particular children, because of their long exposure period to these media during play activities and other behavioral characteristics e.g. ingestion of non-food items and regular hand-to-mouth contact (Paustenbach et al., 1997; Lioy et al., 2002; Butte, 2004; Roberts and Ott, 2007; Hwang et al., 2008).

\subsection{Water and food}

Of all the possible routes for human exposure to DDT, the main pathway in non-malaria areas has been shown to be through ingestion (EHC 9, 1979; Tao et al., 2009). Following a study conducted in Tianjin, China, Guo (2004) showed that ingestion through diet was responsible for $94.9 \%$ of the total intake of DDT while inhalation and dermal contact contributed to only 5.1\%. There is no doubt that crops, open water, and food products in the houses of the Vhembe district are contaminated with DDT as a result of the IRS process.

The $\sum$ DDT levels detected in the drinking water samples from DV constituted mainly $p, p^{\prime}$ - and $o, p^{\prime}$-DDT, and the $\Sigma$ DDT ranged between $0.6 \mu \mathrm{g} \mathrm{L}^{-1}$ and $7.6 \mu \mathrm{g} \mathrm{L}^{-1}$. There were no strong association between the water samples and any specific DDT isomers as indicated by the multivariate analysis (Figs. 2 and 3). The DDT levels in the majority of the water samples $(83.3 \%)$ were below the World Health Organization's (WHO) drinking water guideline value of $2 \mu \mathrm{g} \mathrm{L}^{-1}$ (ATSDR, 2002). Drinking water is obtained from a centrally located community tap in $53 \%$ of homesteads, or, from both a community tap and a natural spring in $47 \%$ of homesteads. The water samples from the community tap and the nearby Luvuvhu River, did, however, not have residues of $\sum$ DDT above the detection limit of $0.5 \mu \mathrm{g} \mathrm{L}^{-1}$. This suggests that the drinking water is probably contaminated on the property where DDT is sprayed.

Chickens and vegetables are a major part of the diet of the VhaVenda people. The dietary information obtained from the questionnaires indicated that leafy vegetables from their own gardens are a main part of their diet, and following insects, chicken is the main source of protein in most homesteads in DV (84\%), and all homesteads in TV. The analyses of the chicken samples indicated that these animals have bio-accumulated high levels of DDT and its metabolites, especially $p, p^{\prime}$-DDE. The chickens are kept indoors throughout the night, and have free range in the village during the day to feed on food particles exposed to the indoor dust and outdoor soil. There is therefore a likely risk for human intake of DDT, and especially DDE, through chickens. The multivariate analyses did show a strong association with $p, p^{\prime}$-DDE and both human serum and chickens, including the muscle, liver and fat samples.

The vegetable samples from DV also had levels of DDT and its metabolites ( DDT median: $25 \mu \mathrm{g} \mathrm{kg}^{-1}$ ). No DDT was detected in samples from TV. The vegetable samples were mainly contaminated with $p, p^{\prime}$-DDT and $p, p^{\prime}$-DDD. The contamination of these plants is likely the result of root uptake of the breakdown products of DDT present in the soil, as opposed to aerial precipitation of DDT during IRS. Although the chicken muscle samples showed high levels of $\Sigma$ DDT (median: $290 \mu \mathrm{g} \mathrm{kg}^{-1}$ ), it has been shown that cooking of chicken could reduce the amount of DDT ingested (Ritchey et al., 1969). This aspect was not investigated in the current study.

\subsection{Association patterns comparing villages}

The multivariate analysis showed remarkably consistent association patterns between the two villages, although TV had many samples below detection limits. In both, $o, p^{\prime}$ - and $p, p^{\prime}$-DDT were strongly associated with indoor air and floor dust, even though the levels were significantly lower $(P<0.05)$ in TV compared to DV. Outdoor soil on the other hand, was much closer associated with the biological matrixes, and once again the levels in TV were much lower than in DV. The profiles of the DDT components in water in DV seemed to have no specific pattern, indicating no direct contamination from IRS. Therefore, since the DDT profile in the serum from DV mirrors the DDT profile of chicken and outdoor soil and much less that of indoor floor dust and air, likely major routes of human uptake in DV is indirect via the outdoor environment and less from the indoor environment. In Fig. 1, axis 3 probably represents the outdoor movement of IRS applied DDT to the outdoor environment with a concomitant transformation of the isomer profile, as indicated by the almost opposite directions of the $p \cdot p^{\prime}$-DDT and $p \cdot p^{\prime}$-DDE vectors. A similar pattern can be seen in Fig. 2, but since there has been no IRS here, other unknown factors may be in force. The DDT is mainly applied indoors and therefore residues must find their way outdoors. Regular sweeping of the floor and removal of the floor dust to the immediate outdoor is common practice. How the DDT profile is transformed from indoor floor dust to outdoor soil remains to be determined, but is likely due to UV from sunlight.

\section{Conclusion}

The results of the current study raise concerns regarding the potential health effects in residents living in an environment shown to be highly polluted with DDT. $\sum$ DDT levels were detected in all of the media analyzed in the homesteads of the DDT-sprayed village. More importantly, the levels measured in the, air, vegetables and chickens were above the WHO guideline values stipulated for safe human intake. DDT levels were below detection limits in water and vegetable samples in the reference village and significantly lower in the air and dust samples compared to the exposed village. In addition, any breast feeding infants would be exposed to air, indoor dust, outdoor soil, and some food, as well as high levels of DDT in breast milk (Bouwman et al., 2006; Sereda et al., 2009), even further increasing health risks to infants.

The findings should encourage a re-evaluation of the necessary safety regulations that forms part of the IRS protocol, to prevent unnecessary contamination of the domestic environment. The results also confirm that harmful levels of DDT are still present in the indoor air approximately 3 months after the DDT has been sprayed. The results show a clear association between the serum levels and the outdoor soil and chicken samples indicating that these components are most likely major routes of human exposure to DDT. However, exclusive routes of human exposure to DDT in local residents cannot be pinpointed. It is possibly the result of a combination of contributing factors, as all the media of the domestic environment analysed in this study was contaminated with relatively high levels of DDT and its metabolites. Education regarding the correct food preparation e.g. washing of vegetables and fruit, cooking of meat and fish as well as promoting personal hygiene i.e. washing of hands after exposure to soil and dust, should form an important part of the malaria control program's future initiatives. This should also include education regarding other control methods like the use of bed nets and management of stagnant water. Similar THE-based studies are recommended in future for continual monitoring of the DDT levels within these exposed communities, to assist in the management of safe and effective IRS, and also to investigate possible related human health effects. THE-based studies may also indicate possible other ways of reducing exposure to DDT and other IRS chemicals, since uptake pathways will be much better documented.

\section{Acknowledgements}

We thank the National Research Foundation (NRF) of South Africa for funding this project. We also thank A. Swemmer of FDA laboratories, W. Louw of the South African Bureau of Standards, E. van der Walt and A. van den Berg of the Agricultural Research Council's Plant Protection Research Institute of South Africa (ARC-PPRI) and S.O.M. Manda of the Biostatistics Unit of the Medical Research Council of South Africa. 


\section{References}

Anastassiades M, Lehotay SJ, Stajnbaher D, Schenck FJ. Fast and easy multiresidue method employing acetonitrile extraction/partitioning and "dispersive solid-phase extraction" for the determination of pesticide residues in produce. J AOAC Int 2003;86:412-31.

Aneck-Hahn NH, Schulenburg GW, Bornman MS, Farias P, De Jager C. Impaired semen quality associated with environmental DDT exposure in young men living in a malaria area in the Limpopo Province, South Africa. J Androl 2006;28(3):423-34.

ATSDR. ToxFAOs for DDT, DDE, and DDD. Agency for Toxic Substances \& Disease Registry. Department of Health and Human Services, USA; 2002. Available from http://www.atsdr.cdc.gov/tfacts35.html. Accessed: 13 November 2008.

Aulakh RS, Gill JPS, Bedi JS, Sharma JK, Joia BS, Ockerman HW. Organochlorine pesticide residues in poultry feed, chicken muscle and eggs at a poultry farm in Punjab, India. J Sci Food Agr 2005;86(5):741-4.

Beard J. DDT and human health. Sci Total Environ 2006;355:78-89.

Bordet F, Inthavong D, Fremy JM. Interlaboratory Study of a Multi-residue Gas Chromatographic method for determination of organo-chlorine and Pyrethroid pesticides and polychlorobiphenyls in milk, fish, eggs and beef fat. J AOAC Int 2002;85(6):1398-409.

Bornman MS, Delport R, Becker P, Risenga S, De Jager C. Urogenital birth defects in neonates from a high-risk malaria area in Limpopo Province, South Africa. Epidemiology 2005; 16:S126.

Bornman R, De Jager C, Worku Z, Farias P, Reif S. DDT and urogenital malformations in newborn boys in a malarial area. Br J Urol 2009 (Electronic publication ahead of print).

Bouwman H, Cooppan RM, Becker PJ, Ngxongo S. Malaria control and levels of DDT in serum of two populations in Kwazulu. J Toxicol Env Health 1991;33(2):141-55.

Bouwman H, Sereda B, Meinhardt RH. Simultaneous presence of DDT and pyrethroid residues in human breast milk from a malaria endemic area in South Africa. Environ Pollut 2006;144:902-17.

Butte W. Sources and impacts of pesticides in indoor air environment. The handbook of environmental chemistry, 4. Berlin: Springer-Verlag F; 2004. p. 89-116.

Cacho J, Salafranca J, Ferreira V, Nerin C. Fast micro-extraction by de-mixture for the determination of organo-chlorine compounds in water. Int J Environ An Ch 1995;60: 23-32.

Chen SH, Xu FL, Dawson R, Jiao XC, Tao S. Adsorption and absorption of dichlorodiphenyltrichloroethane (DDT) and metabolites (DDD and DDE) by rice roots. Environ Pollut 2007; 147:256-61.

Cocco P, Fadda D, Billai B, D'Atri D, Melis M, Blair A. Cancer mortality among men occupationally exposed to dichlorodiphenyltrichloroethane. Cancer Res 2005;65: 9588-94.

Cocco P, Fadda D, Melis M. Reproductive outcomes following environmental exposure to DDT. Reprod Toxicol 2006;22:5-7.

Cohn BA, Cirillo PM, Wolff MS, Schwing PJ, Cohen RD, Sholtz RI, et al. DDT and DDE exposure in mothers and time to pregnancy in daughters. Lancet 2003;361:2205-6.

De Jager C, Farias P, Barraza-Villarreal A, Avila MH, Ayotte P, Dewailly E, et al. Breakthroughs in andrology: reduced seminal parameters associated with environmental DDT exposure and $p, p^{\prime}$-DDE concentrations in men in Chiapas, Mexico: a cross-sectional study. J Androl 2006;27(1).

DoH. General Information on Malaria. South Africa: Department of Health; 2005. Available from: http://www.doh.gov.za/issues/malaria.html. Accessed: 13 Novembe 2008

EHC 9. DDT and its derivatives. Environmental Health Criteria 9, International Programme on Chemical Safety. Geneva: World Health Organization9241540699; 1979.

Eskenazi B, Chevrier J, Goldman Rosas L, Anderson HA, Bornman MS, Bouwman H, et al. The Pine River Statement: Human health consequences of DDT use. Environ Health Persp 2009;117:1359-67.

Guo M. Population Exposure to organo-chlorine pesticides in Tianjin areas. MS thesis, Peking University, Beijing, 2004.
Hayes Jr WJ. Toxicology of pesticides. Baltimore: Williams \& Wilkins Co; 1975. 580 pp. Herrera-Portugal C, Ochoa H, Franco-Sánchez G, Yáñez L, Díaz-Barriga F. Environmenta pathways of exposure to DDT for children living in a malarious area of Chiapas, Mexico. Environ Res 2005;99(2):158-63.

Hwang H, Park E, Young TM, Hammock BD. Occurrence of endocrine-disrupting chemicals in indoor dust. Sci Total Environ 2008;404:26-35.

IPEP. DDT Contamination in South Africa. The International POPs Elimination Project (IPEP). Mark Wells and Llewellyn Leonard, Groundwork, South Africa; 2006.

Kipopoulou AM, Manoli E, Samara C. Bio-concentration of polycyclic aromatic hydrocarbons in vegetables grown in an industrial area. Environ Pollut 1999;106: 369-80.

Lioy PJ. Employing dynamical and chemical processes for contaminant mixtures outdoors to the indoor environment: the implications for total human exposure analysis and prevention. J Expo Anal Env Epid 2006;16(3):207-24.

Lioy PJ, Freeman NCG, Millette JR. Dust: a metric for use in residential and building exposure assessment and source characterization. Environ Health Persp 2002;110: 969-83.

Longnecker MP. Why DDT matters. Invited Commentary. Am J Epidemiol 2005;162(8): 726-8.

Longnecker MP, Klebanoff MA, Zhou H, Brock JW. Association between maternal serum concentration of the DDT metabolite DDE and preterm and small-for-gestationalage babies at birth. Lancet 2001;358:110-4.

LSDI. Lubombo Spatial Development Initiative: Malaria Control Programme; 2003. Available from: http://www.malaria.org.za//lsdi/Overview/overview.html. Accessed: 6 November 2008

McCune B, Grace JB. Analysis of Ecological Communities. MjM Software, Gleneden Beach, Oregon, USA; 2002.

McGlynn KA, Abnet CC, Zhang M, Sun XD, Fan JH, O'Brien TR, et al. Serum concentrations of 1, 1, 1-Trichloro-2, 2-bis(p-chlorophenyl)ethane (DDT) and 1 1-Dichloro-2, 2-bis(p- chlorophenyl)ethylene (DDE) and risk of primary liver cancer. J Natl Cancer I 2006;98(14):1005-10.

Naudé Y, De Beer WHJ, Jooste S, Van der Merwe L, Van Rensburg SJ. Comparison of supercritical fluid extraction and Soxhlet extraction for the determination of DDT, DDD and DDE in sediment. Water SA 1998;24(3):205-14.

Paustenbach DJ, Finley BL, Long TF. The critical role of house dust in understanding the hazards posed by contaminated soils. Int J Toxicol 1997;16:339-62.

Philips DL, Pirkle JL, Burse VW, Bernert JT, Henderson LO, Needham LL. Chlorinated hydrocarbon levels in human serum: effects of fasting and feeding. Arch Environ Con Tox 1989;18:495-500.

Ritchey SJ, Young RW, Essary EO. Cooking methods and heating effects on DDT in chicken tissues. Paper presented in part at the 28th annual meeting of the Institute of Food Technologists in Philadelphia, USA; 1969.

Roberts JW, Ott WR. Exposure to pollutants in house dust. In: Ott WR, Steinemann AC, Wallace LA, editors. Exposure analysis. Boca Raton, FL: CRC Press; 2007. p. 319-46.

Sereda B, Bouwman H, Kylin H. Comparing water, bovine milk, and indoor residua spraying as possible sources of DDT and pyrethroid residues in breast milk. JToxico Env Heal A 2009;72:897-908.

Singh PP, Udeaan AS, Battu S. DDT and HCH residues in indoor air arising from their use in malaria control programmes. Sci Total Environ 1991;116(1-2):83-92.

Tao S, Liu WX, Li XQ Zhou DX, Li X, Yang YF, Yue DP, Coveney RM. Organo-chlorine pesticide residuals in chickens and eggs at a poultry farm in Beijing, China. Environ Pollut 2009;157(2):497-502

Vazquez-Moreno L, Langure A, Orantes C, Flores ME, Bermudez MC. Incidence of pesticide residues in adipose tissue of beef, pork and poultry from plants located in northwestern Mexico. J Muscle Foods 1999;10:295-303.

Vieira EDR, Torres JPM, Malm O. DDT environmental persistence from its use in a vector control programme: A case study. Environ Res 2001;86(2):174-82.

Yáňez L, Ortiz-Pérez D, Batres LE, Borja-Aburto VH, Díaz-Barriga F. Levels of Dichlorodiphenyltrichloroethane and deltamethrin in humans and environmental samples in malarious areas of Mexico. Environ Res 2002;88:174-81. 